\title{
Key points of subway construction technology under complicated geological conditions
}

\author{
China Railway Seven Bureau Group Xi’an Railway Engineering Co., Ltd. Xi’an 710032
}

\section{Summary of Subway En - neering Construction under Complicated Geological Con- dition}

In China's subway construction is the earliest use of the excavation method. With the development of subway construction technology, the current subway construction technology are mainly digging method, dark digging method, shallow buried digging method, shield method and other construction technology. In today's subway project construction, the various subway construction technology interspersed with each other in the construction of subway projects. In the construction of today's subway project, the subway project has the characteristics of constructing the total mileage and the large span of the earth. In this process, the soil geological conditions along the soil will change, and how to change the complex geological conditions the appropriate subway construction technology to ensure the quality of construction is the subway construction in the face of the more difficult problems. In addition, the complex geological conditions in addition to the difficulties caused by the construction of the problem will increase the number of unexpected situations, which requires the construction process in the subway for the understanding of the construction technology to understand in case of sudden situation can be fast and reasonable to solve.

2. Analysis of Construction Technology of Complex Geological Condition

\subsection{Mine construction technology}

Mine law is a traditional method of construction, is the people in the long-term construction practice developed. It is a wooden or steel components as temporary support, to be tunnel excavation after molding. And gradually replaced the temporary corbeling down, and replaced by the overall thick lining as a permanent support of the construction method. Wood components support: the durability of poor resistance to the shape of the tunnel is poor adaptability, support replacement: both trouble and unsafe, and the disturbance of the surrounding rock, therefore, is now rarely used. Steel components support has good durability and adaptability to the shape of the tunnel, etc., the construction cannot be replaced, and more secure. The mouth will be the sodium component as a temporary support of the mining method known as the "backplane method." The steel-wood component supports a "load-structure" human system similar to the ground. It serves as a measure to maintain the stability of the tunnel, very intuitive and effective, but also easy to be understood and grasped by the construction staff. So this method is often used in inconvenient use of shot anchor support tunnel. Due to the design of the lining of the working state and the actual working conditions are inconsistent, and the existence of temporary support - some defects, etc., to limit the degree of its development and application. The basic theory of mining law is based on the impact of the tunnel after excavation, resulting in the formation of loose rock burst state, which at any time may be slumping and dare to the basis
Abstract: With the development of urban and rural construction speed, in the subway project construction, regardless of its construction management, or its corresponding construction technology, have a wide range of applications, in which the complex geological conditions of subway construction technology management is one of them Application is more important and more difficult to control one of the key. However, due to the current construction of the subway project construction technology management, there are still some lack of mature technology problems, which makes the subway construction technology in complex geological conditions in the management of the application process, there are still a variety of problems, including construction safety and construction quality, and thus also seriously affect the social stability and development. This paper analyzes and discusses the main points of subway construction technology under complex geological conditions.

Key words: Complex geological conditions; subway construction; technical points

Published online: 15th July, 2017

of this relaxation load theory, the construction method is to take a split by the order A piece of a piece of excavation, and to avoid the edge of the brace in order to 
ensure safety, so the main complex is the material consumption. Because of this construction method, due to its small working surface, it cannot use large-scale drilling equipment and loading and unloading transport equipment, so the construction progress is slow, taking long construction period with low degree of mechanization, high labor consumption and more difficult to adapt to modern highway construction period the need.

\subsection{Shield construction technology}

Shield construction technology is mainly used in rich in flow sand, fracture and hard rock and weak soil coexistence of geological conditions, with the role of supporting the pressure of the ground layer, but also enough to achieve in the formation of steel structure, with a reliable, safe, environmental protection and fast and so on. If the subway construction environment has a variety of complex engineering geological conditions and hydrogeological conditions, you can consider the use of shield method. The current shield method can be used to adapt to a variety of geological conditions. Not only can build a smaller section of the tunnel, you can also build a large cross-section of the station tunnel. And this method of construction speed, the ground subsidence can also be effectively controlled. Shield construction requires a longer construction time, the use of this approach is also a great investment. Investment is mainly reflected in the manufacture and design of shield and auxiliary equipment. In the use of shield construction method, the first should be carefully surveyed along the engineering and hydrogeological conditions, so that the details are correct. This method has many advantages over other construction techniques. If the ground traffic is crowded, the ground building more and tall, dense distribution of underground pipelines, etc. We must first solve the problem of settlement in the construction of the ground, due to complex construction environment, should not use the open method. And because of the impact of groundwater distribution, the stabil- ity of the surrounding rock is poor, encountered a tight schedule, the use of mining method is clearly inappropriate, the use of shield method should be the best choice, can reflect the economic rationality of the shield method.

\subsection{Shallow Buried Construction Technology}

In addition, the excavation technology is mainly used in the tunnel of underground railway and highway, but it is less in the construction of subway in China because of the need of higher technical requirements. And greater financial support. In 1984, Beijing Fuxingmen subway reentry project, the use of the dark digging technology. Generally should be in accordance with the "New Austrian law" principle design and construction, the use of a strong initial support, the first grouting after the excavation method. Construction principles are: "pipe ahead, strict grouting, short excavation, strong support, fast closed, Qin measured." Generally with $30 \sim 50 \mathrm{~mm}$ steel pipe over the roof of the catheter, and then into the cement or chemical pulp, the formation of "stone body" to enhance the self-stabilization of the surrounding rock. Each excavation footage of about $0.75 \mathrm{~m}$, the first ring excavation, leaving the core soil, pre-spray $5 \sim 8 \mathrm{~cm}$ concrete, frame arch and steel mesh, and then spray $25 \sim 30 \mathrm{~cm}$ concrete, the formation of the initial support, do waterproof layer Do the second lining. In the construction of the Xidan subway station in Beijing, the Ministry of Railways and the Iron House put forward the "double eye method" creatively, as another great breakthrough in China's dark excavation technology is widely used in the subway construction area. As the excavation method can ensure the operation of the ground traffic, so the traffic did not have a greater pressure. Coupled with a reasonable construction program, at the time of the long-span Xidan subway construction in the subway station made a new record.

\subsection{Hybrid construction technology}

The construction of subway tunnels will encounter many different geological conditions, the choice of construction technology must be determined according to the actual needs, in many cases the need to choose two or more construction methods in the construction process, such as shield law and dark excavation method combined with the construction, or shallow buried digging method and the combination of open excavation construction, that is, mixed construction technology. Mixed construction technology and a single construction technology when in compared in the construction it has a more flexibility.

\subsection{Auxiliary construction tech- nology}

Auxiliary construction technology is mainly grouting and high pressure rotary spray method. Grouting method is mainly applied to soft soil construction geological conditions, is the subway construction more commonly used in a construction technology. This kind of construction technology can effectively prevent the tunnel excavation in the process of collapse, subsidence and settlement of the occurrence of Sui, can strengthen the formation and enhance the structure of waterproof performance. The high pressure rotary spray method has the function of strengthening the formation, mainly for auxiliary shallow burial and shield construction, generally in the soft stratigraphic geological conditions.

\section{To strengthen the subway quali- ty control of the key analysis}

The quality of the subway quality also determines the strengthening of the construction of the subway needs us in the construction process to be strictly controlled, and for the development process of the key links for effective control. As the railway construction method is varied, the structure is also more complex, so we need to strengthen the strict control of the quality of the subway.

\subsection{Excavation works}

Due to the differences in geology and hydrogeology between the various regions, it is important to note that even if the construction work is 
still unable to achieve the requirement of waterless construction in the construction process, we need to take different Measures to better consolidate the construction of the various strata. For example, small pipe grouting, deep hole grouting and temporary support and other measures to better strengthen the construction of the safety of construction. There are many measures to strengthen the construction of the building, the detection method is not perfect, and some tests cannot even better achieve the effect of strengthening the consolidation, therefore, better quality of reinforcement is particularly important. In the process of artificial excavation, we need to choose different construction methods according to different strata, and better strengthen the pre-exploration, through the steps of excavation and core soil retention and other ways to complete.

\subsection{Excavation project}

For the digging project, the key point of its quality control is the support of the foundation pit, in general, the subway project is a deep foundation pit, the support of the program we need to demonstrate in advance, in the construction process also need to follow Designed drawings for construction.

\subsection{Shield Engineering}

Shield engineering quality control of the key and the key link is to constantly adjust the installation of shields, shield machine posture adjustment. As the attitude of the shield machine is to strengthen the control, select the appropriate line, and constantly strengthen the quality of the segment itself. In the adjustment process of the shield machine we need to better in accordance with the correct line and elevation of mining, shields are provided by the production of the manufacturers, and therefore need to enter the factory inspection before they can be in the construction process for better use.

\subsection{Waterproofing works}

At present, because the subway project is a variety of materials used, the construction method is relatively more complex, so we need to strictly in accordance with the level of waterproof to carry out strict implementation, can do not leak. In the construction process should also be on the water-proof materials into the factory inspection and operation of the quality of strict checks, do a good waterproof layer of the base. Constantly strengthen the joints and other special parts of the control and management.

\section{Conclusion}

Since the new period, the development of China's subway project has entered a new stage. In order to cope with the increasingly severe urban traffic congestion problems through the active construction of the sub- way to alleviate the traffic pressure, the subway through the construction of underground transport network, so that the urban transport system in the original ground traffic on the basis of a greater transport capacity, The whole city traffic system in the last piece of short board, greatly facilitate the people travel. Compared with the construction of the ground road, the subway project will be affected by the underground geological conditions in the process of construction, so the requirements of the construction technology is higher, the technical difficulty of the main reason is due to the complex underground geological conditions in the subway construction need to use a variety of construction techniques combined to ensure the quality of subway construction.

\section{References}

[1] ZHENG Yan. Deformation Mechanism of Subway Construction Strata under Complex Conditions and Study of Bridge Pile Failure [D]. Liaoning Technical University, 2013.

[2] Cai Pan, Cui Wei. Construction Technology of Subway Complex Geological Condition [J]. Science and Technology Innovation Guide, 2013,15: 101. 